\title{
LETTERS TO THE EDITOR
}

Re: Cooper MA, Tinmouth JM, Rabeneck L. Registered nurseperformed flexible sigmoidoscopy in Ontario: Development and implementation of the curriculum and program. Can J Gastroenterol Hepatol 2014;28:13-18.

To the Editor:

I read with interest the article by Cooper et al (1) in the January 2014 issue of the Journal describing a program for colorectal cancer screening performed by registered nurses (RNs). Cooper et al are to be congratulated for their hard work. However, I would point out that the statement "the first formal RNFS training program began in Ontario in 2005" is incorrect. We conducted a similar program at The Scarborough Hospital (Toronto, Ontario) from 1999 to 2002 (2) and have reported the findings from $>1800$ individuals examined by RN-performed flexible sigmoidoscopy (RNFS) (3). Our program, similar to that of Cancer Care Ontario (CCO), included didactic and technical training of nurses according to a formal protocol. Furthermore, we conducted extensive discussions with the College of Nurses of Ontario, the Registered Nurses Association of Ontario (RNAO), the College of Physicians and Surgeons of Ontario, the Canadian Medical Protective Association and various committees of The Scarborough Hospital, all of whom established policies that permitted our nurses to perform the procedure. We are pleased that we have, thereby, eased the process for subsequent RNFS because enabling policies have been in place since 1999.

Regarding the program described by Cooper et (1), there were several unanswered issues in its methodology. First, did the RNs use a $60 \mathrm{~cm}$ flexible sigmoidoscope or a colonoscope? There would be major differences in the extent of the examination between the two instruments. Second, were the nurses permitted to biopsy? It is inferred that pathology was reviewed. If so, that would constitute a major advance in the policy of the RNAO and the Ontario College of Nurses, which previously would not allow RNs to perform tissue sampling. Third, what were the criteria for recommending colonoscopy? Finally, it was stated that a physician was required to be nearby for troublesome cases and interpretations. How often was that physician accessed and how was he remunerated? Overall, the cost per case needs to be reported to demonstrate that there is a benefit over physician operator. The fee for flexible sigmoidoscopy (FS) performed by physicians is approximately $\$ 55$, plus consulting fee, which is not a great deal, particularly if the operator is a family doctor.

The reported colorectal cancer detection rate of $0.51 \%$ compares favourably with our results. Additional data are necessary to further evaluate the efficacy of the program. How did the RNs perform in terms of insertion length and procedure time? What was the rate of recommended colonoscopy and what was the compliance? Were the cancers detected at FS or at subsequent colonoscopy? It would also be of interest to know whether the RNFS centres were located in communities where there was reasonable access to colonoscopy or in underserviced areas that are most in need of access to screening. Most importantly, what was the degree of acceptance of FS versus colonoscopy by local family physicians, given they are the gatekeepers?

Above all, the efficacy of the program will be measured by longterm statistics, particularly the incidence and mortality of colorectal cancer following FS. Are measures in place to follow patients in a population-based rather than registration fashion? The merits of the program will be determined not by its methodology, which is not novel, but by its performance. I look forward to further reports regarding this excellent initiative.

Our program was terminated, in part, because of the rising profile and availability of colonoscopy. Referring doctors, encouraged by colonoscopists, began to believe that there was a superior alternative, and enthusiasm for FS waned. Part of our rationale for introducing RNFS was the potential to provide some form of endoscopic screening to underserviced areas, which may still be a worthy objective. However, in an era in which colonoscopy rates are rising, and when Cancer Care Ontario and The Ministry of Health and Long-Term Care are both endorsing fecal occult blood testing and developing strategies to increase access to colonoscopy, RNFS may have difficulty finding its place in the smorgasbord of screening modalities available today.

Theodore Shapero MD FRCPC Scarborough General Hospital Medical Mall Toronto, Ontario

\section{REFERENCES}

1. Cooper MA, Tinmouth JM, Rabeneck L. Registered nurse-performed flexible sigmoidoscopy in Ontario: Development and implementation of the curriculum and program. Can J Gastroenterol Hepatol 2014;28:13-18.

2. Shapero TF, Alexander PE, Hoover J. Colorectal cancer screening: Video-reviewed flexible sigmoidoscopy by nurse endoscopists: A Canadian community-based perspective. Can J Gastroenterol 2001;15:441-5.

3. Shapero TF, Hoover J, Paszat L, Burgis E, Hsieh E, Rabeneck L. Colorectal cancer screening with nurse-performed flexible sigmoidoscopy: Results from a Canadian community-based program. Gastrointest Endosc 2007:65:640-5. 


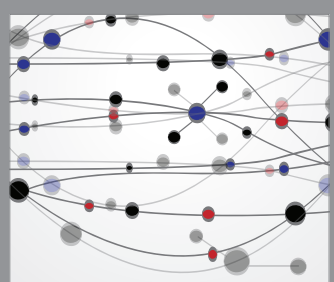

The Scientific World Journal
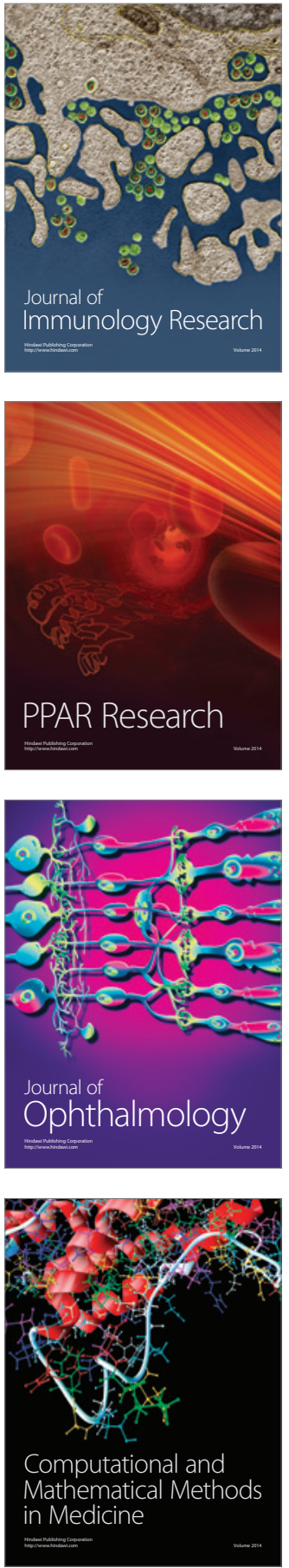

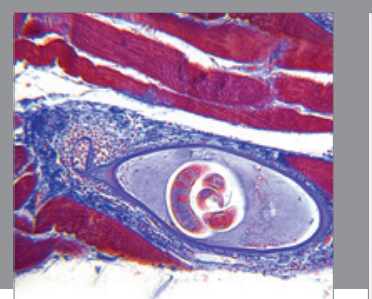

Gastroenterology Research and Practice

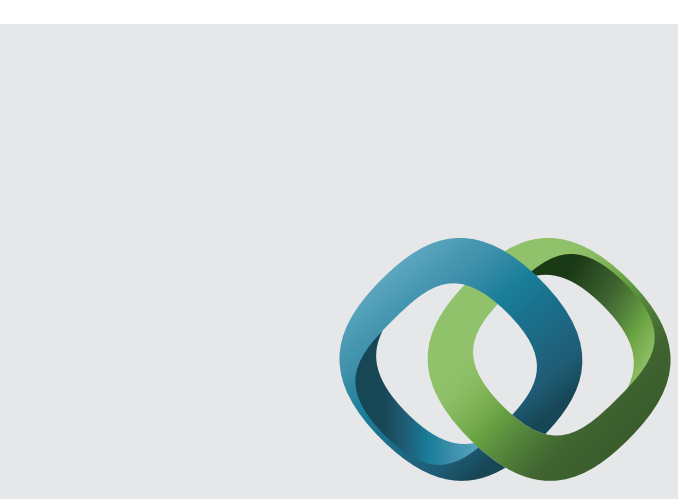

\section{Hindawi}

Submit your manuscripts at

http://www.hindawi.com
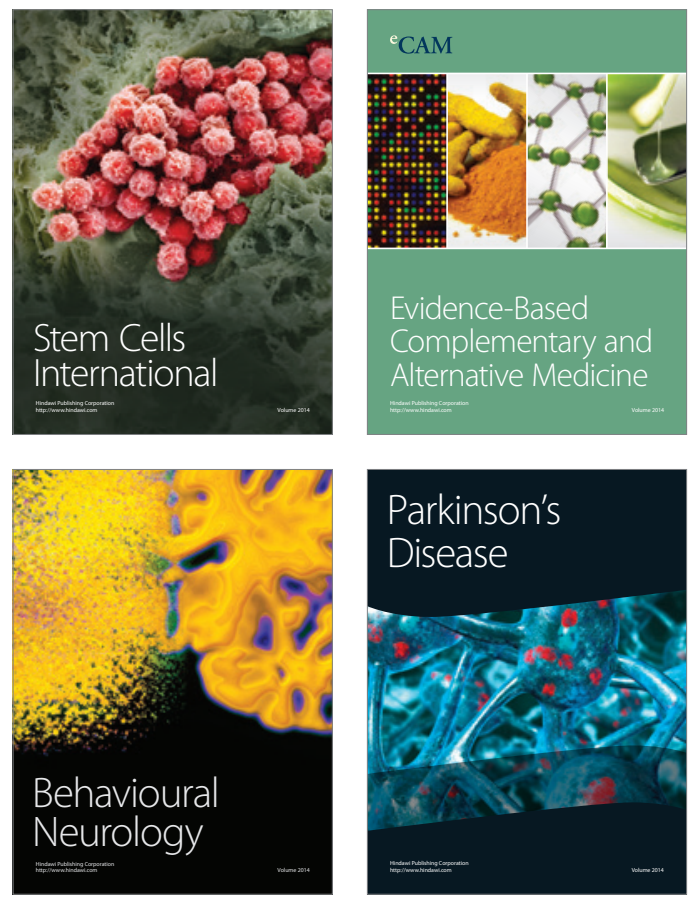
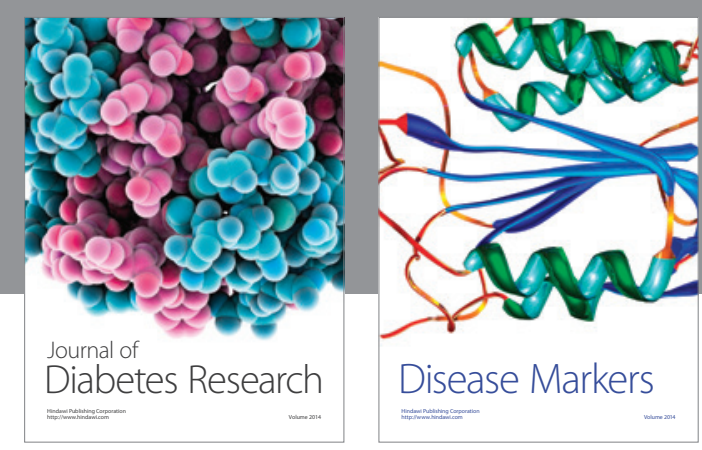

Disease Markers
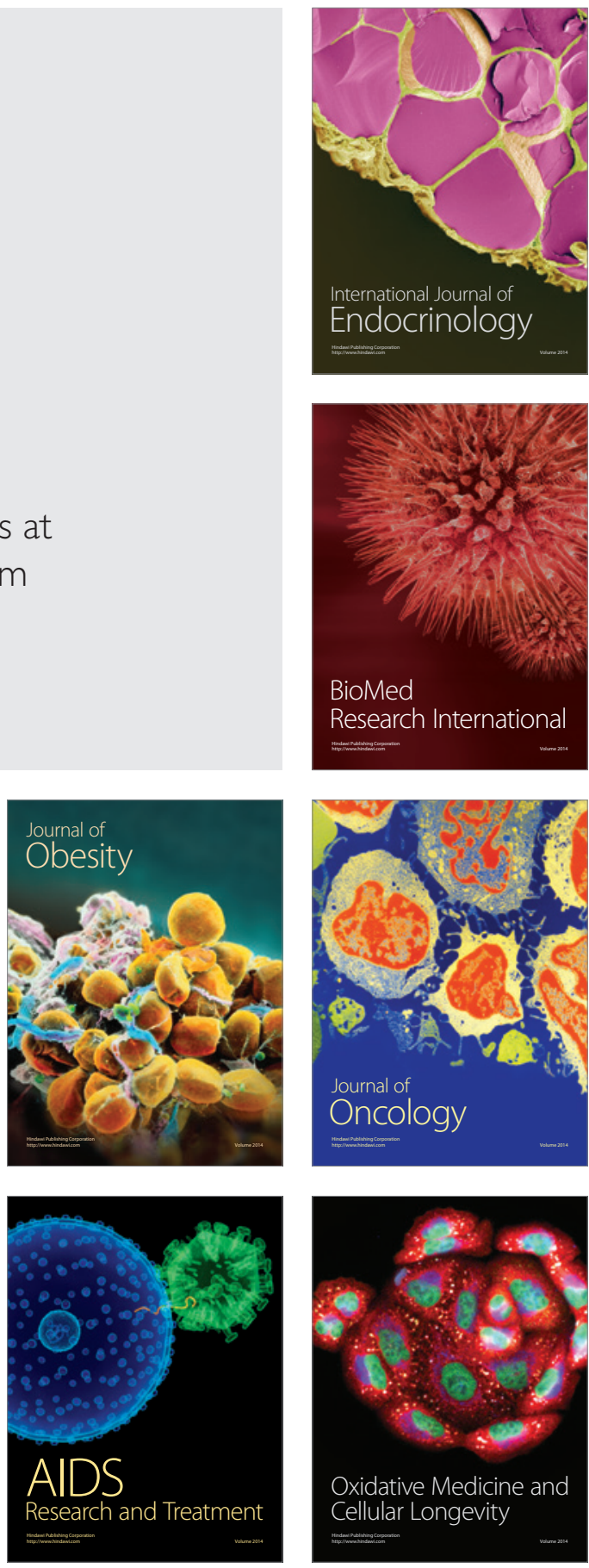